\title{
Importance of the use of interactive methodologies in primary education: gamification. Didactic proposal
}

DOI: $10.46932 / \mathrm{sfjdv} 2 \mathrm{n} 1-020$

Received in: November 1st, 2020

Accepted in: December 30th, 2020

\author{
Juani González Muñoz \\ Graduated as an elementaryschool teacher, \\ Institution: RG Formación \\ Calle Rosalía de Castro, 44, 30107 Murcia \\ Belén Cánovas Calderón \\ Graduated as an elementaryschool teacher, \\ Institution: RG Formación \\ Calle Rosalía de Castro, 44, 30107 Murcia \\ Rocío Muñoz Melgar \\ Graduated as an elementaryschool teacher \\ Institution: RG Formación \\ Calle Rosalía de Castro, 44, 30107 Murcia \\ Jose María Rabal Alonso \\ Professor ISEN Centro Universitario \\ Institution: Universidad de Murcia \\ Calle Campus Universitario, 12, 30100 Murcia \\ E-mail: josemaria.rabal@um.es
}

\begin{abstract}
It is nothing new that positive emotions are related to greater and better learning capacity and it is this situation that, especially considering the current global pandemic situation with all the impact it has created on a psychological level - and therefore, directly or indirectly at the educational level — creates the pressing need to offer a methodology and class dynamics that arouse the interest of students and create motivation for learning. Faced with this situation, this work offers a detailed synthesis of a methodology that includes these requirements, gamification, also offering a series of suitable activities for use in Primary Education classrooms.
\end{abstract}

Keywords: Gamification, methodology, didactics, school organization, motivation.

\section{INTRODUCTION}

In the field of education, there are numerous advances every day, there are many innovations in the resources and ways of teaching, thus achieving new ways of acquiring learning in students. Precisely because of these changes and new methods, teachers must keep up-to-date and in constant training, being decisive and original when imparting their teaching. 
To specify a bit regarding didactic innovation and new ways of teaching, we will delve into the methodology of gamification. This methodology consists of bringing play closer to learning, and vice versa. In the ages comprised by the primary stage, which range from six to twelve years of age, there is an essential component that plays a leading role in many aspects of children's lives, such as cognitive, affective, motor aspects ... This component is the game, and therefore it can be used in the classroom to learn through it.

As Kapp (2012) points out, it is "the use of mechanisms, aesthetics and the use of thought to attract people, incite action, promote learning and solve problems" (p. 9). Therefore, we understand gamification as a strategy that uses elements of the game in non-playful contexts, pursuing specific objectives in order to enhance student motivation and a meaningful and playful experience.

As stated by Raquel Ocón Galilea (2017), gamification must involve three elements: motivation, involvement and fun. However, these three elements must always be applicable to the classroom, regardless of the methodology we carry out.

In this sense, it is clear the fact that mechanized techniques do not contemplate motivation on the part of students, but only taking into account intrinsic motivation, skills and competences such as creativity and critical thinking, among others, is personal development achieved of the students.

Taking into account immediate needs and technologies, current inclinations and concerns need an educational response to young people in the school context. Teachers are responsible for providing this answer, seeking methodological innovations that enhance the motivation and commitment of students, providing them with effective resources for meaningful learning. In fact, students achieve this learning and become more engaged when they are motivated. (FERNÁNDEZ; OLMOS; ALEGRE, 2016).

Gamification is used as a learning tool in any area and for the development of attitudes and autonomy of the student. (CAPONETTO; EARP; OTT, 2014). However, if students do not show any interest in learning, the teaching-learning process can be impaired by gamification. (TORI, 2016). In the same way, the relationship between the challenges proposed to the students and their abilities must be taken into account, if a challenge is too easy for them, they will lose motivation and abandon the process, while if a challenge is too difficult, get frustrated and quit in the same way. In this process, the two existing types of motivation must be taken into account. In the first place, the extrinsic that, according to Palazón Herrera, (2015) is the one that has been used for years by compensating students for their grades, achievements, digital badges. And, on the other hand, intrinsic motivation, which is the one that is born from the student towards what interests him. Valderrama (2015) points out that play is an intrinsically motivating activity, through which students experiment and develop social and emotional skills. 
That is why the use of the game in the classroom takes on special relevance, finding today the use of gamification as a certain trend.

Some elements that usually appear in Gamification and what makes it an enriching experience in the classroom are:

- Goals and objectives: They promote motivation in the classroom, helping to solve problem situations and carry out activities directed by the tutor

- Rules: They are established so that students have guidelines to follow and there is an order within the class. These rules can be to win or lose points, respect the turn to speak ...

- The narrative: It is essential that the tutor present the game in an adequate way and involving all the students.

- Freedom to choose: Enabling students to choose their character, the route to follow or the objectives they want to achieve provides that they develop the competence of a sense of initiative and an entrepreneurial spirit.

- Freed to make mistakes: Just as we give students the option to choose what they want to do, we must encourage players to make mistakes and rectify.

- Rewards: They have to be related to the game that is being carried out, for example new lives, virtual rewards, reinforcement in exams ...

- Feedback: In which the progress of the students in the game is depending on their achievements that are measured through resources such as progress bar, performance statistics ...

- Visible status: Have a kind of meter where the participants in the game can see in a range what their progress has been.

- Cooperation and competition: This item is essential for all students to feel integrated in the classroom. The teacher's role is that students create groups, help each other ...

- Time restriction: This could be used so that students try harder in less time, since seeing that they need to achieve something in a period of time increases productivity.

- Progress: It is convenient for students to observe their progress and be motivated to continue achieving objectives. It can be measured through progress bars, learning development tutorials ...

- Surprise: Unexpected items can be included to help players stay focused.

Within the classroom there is a great diversity of students, and therefore of different interests. This means that, according to Marczewski (2013), the different types of players can be classified: Explorers, socializers, thinkers, philanthropists, achievers, and revolutionaries.

In order to be able to take advantage - curricularly and significantly - of the use of the game in the classroom, the role that the teacher carries out during the use of this strategy is highly binding with 
the result obtained at the aforementioned levels —interest, learning, motivation. ..- . That is why the teacher must be a guide in the game, adapting the rules established by traditional games to the classroom. In the first place, the teacher must establish the objectives he wants for his teaching planning within Gamification. Taking into account the aforementioned, the types of students and therefore the players that we have in the classroom must also be taken into account, in this way it will be easier to propose one type of game or another. In the third instance, the pedagogical and technological resources will be chosen taking into account the possibilities of each center. The teacher will then guide the path that the students must follow as players creating different strategies. Finally, an evaluation will be carried out where the evolution of the students will be reflected.

As important as the approach and development of the activity, as well as the role of the teaching role, will be the meticulous review and assessment that we make both of the learning acquired by the students as well as the teaching-learning process. In this sense, the evaluation is closely linked to how the students develop in the game, and it must also be very little intrusive as suggested (Shute, 2011; Shute, Ventura, Bauer, and Zapata-Rivera, 2009), that is, it must be as less significant as possible, otherwise a loss of interest can occur.

\section{ACTIVITY 1: “WE CATCH OUR EQUIVALENT PARTNER".}

This activity is proposed for the 5th year of Primary Education, within the Mathematics classroom and is titled "We catch our equivalent partner". It consists of an application and reinforcement activity, and it will be carried out in a session after trying and explaining the necessary content.

In the first place, the teacher will perform 21 roles with one function each. There will be seven groups of numbers, each group represents the same quantity but expressed in a different way. Each student will have a role, that is, they will represent a fraction, a decimal number or a percentage. Once they know what the role of each one is, they will have to find among all the classmates which roles are equivalent to their number. That is, if a student has a piece of paper that expresses the decimal number 0.5 , he will have to find a partner who represents $50 \%$ (which is its equivalence expressed as a percentage) and another partner who represents $1 / 2$ (which is its equivalence expressed in a reduced fraction). Once the game begins and they find their equivalent group, they will be placed in a row so that they will be placed in the order in which they finish the game.

A first game will be held as a contact point so that they assimilate the terms of the game. Once this first game is made, the papers will be distributed again several times but, these times, timing the games, so that we can achieve with practice that each game lasts less time. At the end of each game, each group will be supervised. That is, group by group they will show what number they represent, what their 
equivalent numbers are and what process they have carried out to obtain that result. In this way, the teacher makes sure that the game is played effectively and solves possible errors.

Throughout the activity, the teacher will guide the students, solving possible doubts, and an active learning by the student, through the constructivist model.

Among the necessary material we find the seven groups of numbers distributed in 21 pieces of paper with the corresponding numbers and a timer that will be provided by the teacher.

On the other hand, during the necessary explanations the students will be located in their corresponding places. Once the games of the game begin, the students will go around the classroom trying to find their equivalent classmates.

An example of this could be seen on figure 1 .

Figure 1. We catch our equivalent partner

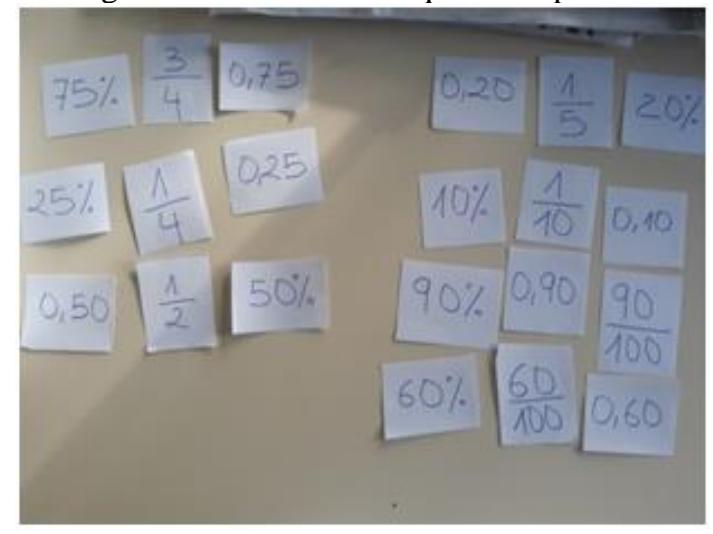

\section{ACTIVITY 2: "SPELLING LOTTERY".}

This activity is proposed for the 5th year of Primary Education, within the Spanish Language and Literature classroom and is titled "Spelling Lottery". It consists of a review activity, and it will be carried out in a session after trying and explaining the necessary content.

This preparation is based on the traditional lottery game and can be played in groups or in a large group. Sharp, flat and square word cards and index cards will be needed to cover the correct word. The teacher will have a sheet of paper with the different words on the cards (and their correct accentuation) and will say the names randomly. Students with cards must cover their word with the correct card (sharp, flat or esdrújula word with accent or sharp or flat word without accent). The students will be able to sing "line" or "bingo" and, after this, the cards will be corrected in a large group to check the solution and resolve all possible doubts. Therefore, it is necessary that the accentuation contents have been previously seen.

An example of this activity could be seen on figure 2 . 
Figure 2. Spelling lottery

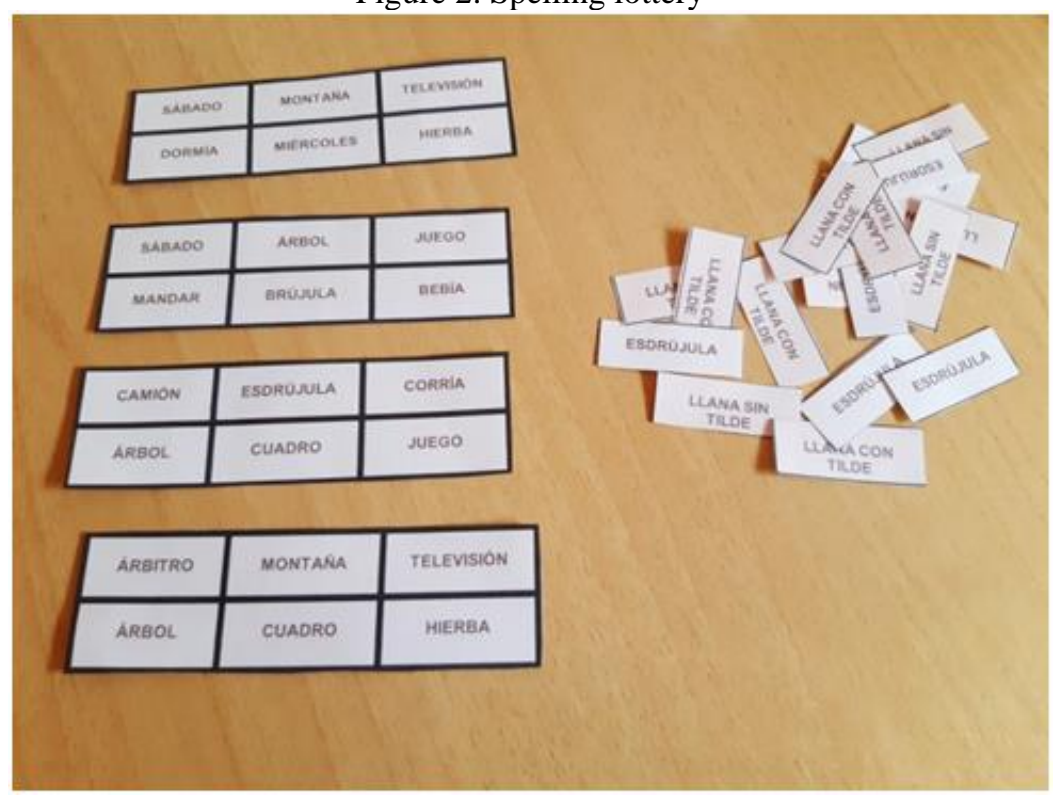

\section{ACTIVITY 3: "WHAT DO WE KNOW?"}

This activity is proposed for the 5th year of Primary Education, we can apply it within any area and is entitled "What do we know?" It consists of an activity to detect previous knowledge. The specific objective is to obtain prior knowledge about specific content and it will be carried out in 60 minutes.

Among the necessary materials we find the classroom, the class computer, the projector, a plickers account with the necessary information of the students, their corresponding application labels and the questions asked to be answered.

Through the application of "Plickers", we will collect results on the knowledge that students have about the contents. The plickers is a tool for examining students in a fun and dynamic way. Through multiple choice questions that are displayed on the projector, each student will answer the questions with their corresponding card. Each card has a different geometric shape and on the 4 sides of said figure are the letters A, B, C, or D. To answer the answer that they think is correct, they must lift the figure with the corresponding letter on the upper side. Once the cards are exposed, the teacher with the application of the "plickers" on the mobile will sweep all the students, so that all the answers to these questions will be recorded.

\section{ACTIVITY 4: WHO IS WHO?}

The following activity has been proposed and developed for the 4th grade classroom in the Language area, although the difficulty of carrying it out in any course can be reduced or increased. The objective of its development is for it to serve as a review of grammar content, this being a playful and active review by the students. The activity in question is an adaptation of the famous game who's who. 
The content in this case is the adjective. The materials needed to make the game are post-it. To develop the activity, the students will join pairs. The game consists of one member of the pair sticking a pos-it on his forehead on which his partner has written a word, which he must guess through questions, in which can only use adjectives (in any of their degrees -positive, comparative or superlative-) Some examples of questions that the students could ask and would be valid in the activity are: Am I hairy? Am I faster than a lion? Am I huge? Instead of do I have hair? Do I run with speed? Through the questions and their answers the students will come to the meaning. The game can be facilitated by assigning categories, for example, the teacher can say, " in this round you have to guess animals ".

\section{ACTIVITY 5: WE PLAY KAHOOT}

This activity introduces knowledge for the beginning of a new mathematics topic, which will consist of an approach to decimal numbers and their use in the students' daily lives (prices, height, weight ...). In this way, it will be possible to find out their previous ideas and be able to evaluate to what degree they have them, substituting the cards or typical oral questions in these sessions for this game, which is carried out using a digital tool whose name is Kahoot. This application allows you to gamify the classroom with multiple-choice questions that students must answer. The students are adding points in each success and according to the response speed, appearing a ranking of score at the end of the test, as well as a podium with trophies for the best results.

This specific activity is designed for the 4th year Primary Education math classroom and its main objective is to identify decimal numbers, recognizing that numbers are not exact and that between one and two (for example) there are infinite numbers. In addition to knowing them, the objective of knowing how to apply decimal numbers and find their relationship in real contexts is also pursued.

Regarding the development of the task, it will be necessary for the students to be grouped in pairs, which will share a device (chromebook, tablets ...) to answer the projected questions. However, depending on the availability of devices in the center, it can also be done individually. Once paired, the Kahoot prepared previously by the teacher will be carried out, which may contain questions very similar to the following shown:

1. Is there a number between 1 and 2 ?

2. What parts does a decimal number have?

3. What element separates the parts of the decimal number?

4. How do you read this decimal number: 25.45 ?

5. How do you write: two tens and five tenths?

6. If we want to approximate 3.9 to unity, is it close to 3 or 4 ?

7. I want to buy a computer, but it costs 399.99 , what would I spend approximately?

8. Order the following heights from largest to smallest: $1.55,167,1.45$.

9. What is $1.5+1.5$ ?

10. Am I going to learn a lot throughout this unit? 
It should be noted that each question must have several answer options, of which only one will be correct. This type of activity, in addition to being a playful introduction to the syllabus, allows us to see which content is most difficult for the students and therefore which of them will have to be emphasized.

\section{ACTIVITY 6: MEMORY OF EMOTIONS}

Gamification can not only be extrapolated to strictly theoretical content corresponding to certain areas, but it can also be carried out for the treatment of transversal content, such as, in this case, the recognition of emotions.

In this activity the game will be developed by the students themselves, so it will be necessary to spend time preparing the materials for them. In this case, the students must write eight sentences on six cardboard cards, each one referring to an emotion, in addition to the already known anger, sadness, anger, fear and joy, the teacher will suggest others such as: love, surprise , worry, shame, anxiety, happiness, shyness ... On the other hand, in another six cards they should draw a picture that represents each of the emotions described in the previous cards, so that there is a relationship between each sentence and drawing , being able to form pairs between them. Once this is done, the students will join in pairs, these being random and they will start the game developed by them. Each pair will mix all their cards and put them face down, so that, in turn, they will have to pick up two by two, until a phrase coincides with their respective drawing, so that the two belong to the same emotion, being able to combine your own cards with your partner's, as long as, as I have already said, they belong to the same emotion. In this way, gamification is used to recognize emotions and also works on writing and reading, both texts and images, related to emotions. An example of memory of emotions could be the following: being able to combine their own cards with those of their partner, as long as, as I have already said, they belong to the same emotion. In this way, gamification is used to recognize emotions and also works on writing and reading, both texts and images, related to emotions. An example of memory of emotions could be the following: being able to combine their own cards with those of their partner, as long as, as I have already said, they belong to the same emotion. In this way, gamification is used to recognize emotions and also works on writing and reading, both texts and images, related to emotions. An example of memory of emotions could be seen on figure 3 : 
Figure 3 Memory

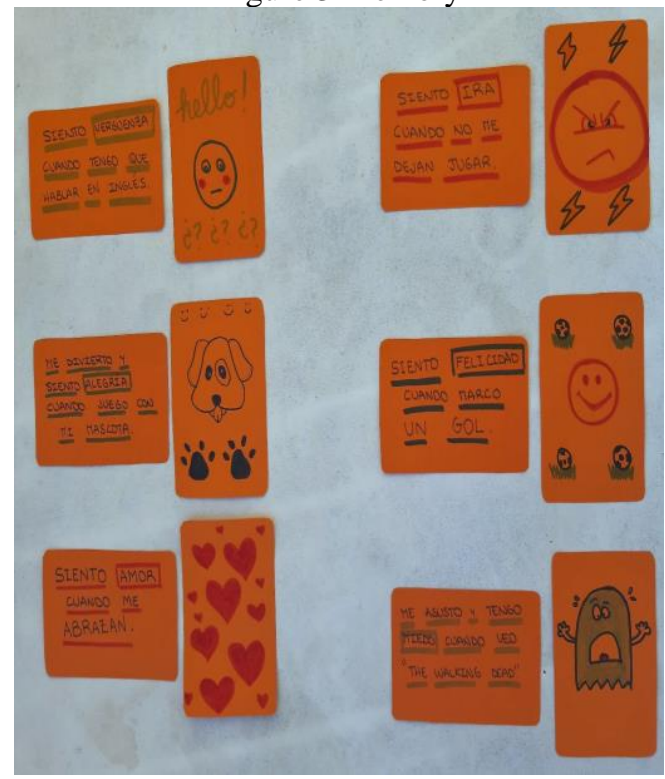

\section{CONCLUSIONS}

Finally, it is worth highlighting the many possibilities offered by this methodology when carrying out the processes of design and application of activities in the classroom, since through gamification, the activities can be adapted to the level of development of the students increasing or reducing the difficulty, thus obtaining numerous variants that adapt to the characteristics of the group in general and of each student in particular, and in turn, making them feel comfortable during the development of their learning process.

On the other hand, and to conclude this article, it is found that gamification is a great tool for education, with which difficulties in the classroom can be addressed. Play and education are two connected concepts that allow students to explore, experiment and test different contexts.

Currently, one of the main problems in the reality of the classroom is the lack of motivation of the students. Consequently, using gamification makes it easier for students to get involved in the learning process, strengthening and putting into practice their personal skills, in the same way that they learn a series of contents in a more entertaining and fun way. Therefore, the importance of this element is highlighted since it favors cognitive development, emotions, socialization processes and, in this way, responds to the needs and interests of students.

Gamification is not a straight path to follow with students, but we must take into account as teachers the educational context in which we are going to focus it. This means that we must know very well the elements, rules and principles of this methodology focused on the game, in order to be able to focus it appropriately within the classroom. Creating this game dynamic is not as simple as it seems since 
it may seem unforeseen such as: the weather, the students not understanding the game or simply not adjusting to the Curriculum.

Finally, add that gamification is a good instrument that can be used in the classroom since: it increases the motivation of the student body, generating cooperation between classmates to solve the game, promoting a safe environment for learning. 


\section{REFERENCES}

CAPONETTO, Ilaria; EARP, Jeffrey; OTT, Michela. Gamification and education: a literature review. In: EUROPEAN CONFERENCE ON GAMES-BASED LEARNING, 8., 2014, Berlín. Actas... Berlín: University of Applied Sciencies, 2014. p. 50-57.

FERNÁNDEZ, Anabel; OLMOS, Julia; ALEGRE, Joaquín. Pedagogical value of a common knowledge repository for business management courses. @ Tic: Revista d'Innovació Educativa, Valencia, n. 16, p. 39-47, 2016.

Jofré, D. E. R. (2018). Gamificación de espacios virtuales de aprendizaje. Contextos: Estudios de Humanidades y Ciencias Sociales, (41).

Kapp, K. M. 2012. The gamification of learning and instruction: game-based methods and strategies for training and education. John Wiley \& Sons.

Ortiz-Colón, A. M., Jordán, J., \& Agredal, M. (2018). Gamificación en educación: una panorámica sobre el estado de la cuestión. Educação e Pesquisa, 44.

PALAZÓN-HERRERA, José. Motivación del alumnado de educación secundaria a través del uso de insignias digitales. Opción, Maracaibo, n. 31, p. 1059-1079, 2015.

TORI, Romero. Tecnologia e metodologia para uma educação sem distância. EaD EmRede, Porto Alegre, v. 2, n. 2, p. 44-55, 2016.

VALDERRAMA, Beatriz. Los secretos de la gamificación: 10 motivos para jugar. Capital Humano, Madrid, n. 295, p. 73-78, 2015. 